\title{
Beyond Us Versus Them
}

$I^{n}$ $\mathrm{n}$ the beginning, there was a national debate. The debate, which began in the early 1990s, was about the excess number of medical specialists relative to primary care physicians. The debate originated in the notion that specialty care was contributing disproportionately to the unsustainable inflation in the price of delivering medical care to America's workforce. This notion was founded, in part, on the common sense suppositions that physicians do what they know how to do and specialists collectively know how to do more and more expensive things to patients. Therefore, reducing the number of specialists and reducing access to them would drive down the cost of care. Elaborate calculations compared the ratio of specialists to generalist physicians in the United States with the ratio of similar physicians employed by managed care companies and the ratios of similar physicians in Canada and Europe. These calculations alerted the medical community and public policy makers that cost containment meant specialist containment. ${ }^{1,2}$ The workforce issue, and therefore the financial issue, would be solved by a plan producing $50 \%$ specialists and $50 \%$ generalists. ${ }^{3}$ It was endorsed, it was implemented, and it was the close of the first chapter.

However, in the firmament there arose voices arguing that each medical specialty must be considered independently. An admission by the gastroenterology community that there were too many gastroenterologists ${ }^{4}$ should not be taken to mean that there were too many other medical specialists. There might be just the right number of some specialists, like oncologists ${ }^{5}$ and not enough of others, like nephrologists ${ }^{6}$ to care for the aging population with its ever-increasing frequency of cancers and end-stage renal disease. And so the plan was to make adjustments, such as longer training periods and fewer training positions for future gastroenterologists. It was endorsed, and it was the end of the second chapter.

And the professional conscience of medicine decreed that, whatever limits were placed on specialists, we must be vigilant in maintaining the quality of care. Thus were born outcomes researchers, who could "link the type of care received by a variety of patients [whether specialists or generalists provided that care] to positive and negative outcomes in order to identify what works best for which patients." 7 The plan was to devise tools to assess how care is provided, how much is given, how much it costs, and how good it is. It was endorsed, it was good, and it was the beginning of the current chapter.

In this issue, Harrold, Field, and Gurwitz make an important contribution by examining the studies published since 1981 that directly compared generalists with specialists in regard to their knowledge and the patterns and outcomes of the care they provided. ${ }^{8}$ Although Harrold and colleagues found a rich literature with more than 285 articles about what these physicians know and do, 243 of these articles were not included in the study because they did not directly compare generalists and specialists. Over half the articles that were included dealt either with care for cardiovascular diseases such as acute myocardial infarction, hypertension, and angina, or with "preventive care" such as compliance with recommended guidelines for mammography, Pap smears, and periodic health examinations. Although several studies compared how specialists and generalists managed specific conditions such as peptic ulcer disease, ${ }^{9}$ AIDS, ${ }^{10}$ and renal failure, ${ }^{11}$ a disappointingly small number of studies compared how they managed such common and important conditions as diabetes, asthma, arthritis, and breast cancer.

As a medical specialist one might think that the conclusions of this review would reinforce the intuition that medical specialists are more knowledgeable about their particular specialty than generalists and are more likely to institute effective, sometimes lifesaving, prevention and treatment measures. Shouldn't we specialists celebrate that, under the care of a cardiologist, patients with acute myocardial infarction are more likely to survive the acute event and leave the hospital on a beta blocker (12), that when cared for by a cardiologist patients with severe congestive heart failure also have a survival advantage (albeit at an increased cost) (13), that patients with asthma who are cared for by an allergist report a "quality of life" advantage (14) and that care by a neurologist results in increased survival for patients having had a nonhemmorrhagic stroke (15)? Shouldn't we specialists argue that in the examples where care by a specialist compared to a generalist did not improve outcomes, such as low back pain, chronic obstructive pulmonary disease, osteoarthritis or non-insulindependent diabetes mellitus the failure to observe differences is because little that we do for many illnesses has been rigorously shown to have an impact on natural history or survival (back pain or COPD) or that the short term outcomes measurements could not have possibly shown a specialist benefit when the intervention takes a long time to improve the natural history of the disease (diabetes)

On the contrary, this review is poignant in highlighting two of the essential roles of the medical specialist that need improvement or continuous effort. As subspecialists from all of internal medicine pondered their potentially constricted future roles, a recurring theme was the importance of specialists as educators of their generalist colleagues as well as their patients (16). When generalists use clearly effective treatments for common diseases less often than specialists, we must ask how we, as specialists, can improve methods of teaching and implementation with a goal of equivalent patient care (17). How can communication and pedagogic skills be better integrated into our specialty training programs? Having identified a role, and now a need to play that role, specialists must think more seriously about their responsibility as educators. If the payers are genuinely concerned about "quality of care" to their clients it is imperative to develop incentives for the teaching role of specialists. 
Perhaps even more important is the role of specialists as researchers. There is a discrepancy between the explosion in new knowledge created by medical specialists and the amount of evidence showing how this knowledge benefits patients. We should collectively lament that the review by Harrold and colleagues found only a handful of reports about interventions that unequivocally affected the outcome of disease. Specialists, generalists, and research funding agencies must work together to focus more resources on identifying interventions that prevent or alter disease.

In the end, it is not about us versus them or who can do what better; it is about making a difference in our patients' lives. For specialists, it is our duty to teach and our lifeblood to discover.-MARK S. KLEMPNER, MD, Tufts University School of Medicine, Boston, Mass.

\section{REFERENCES}

1. Weiner JP. Forecasting the effects of health reform on US physician workforce requirements: evidence from HMO staffing patterns. JAMA. 1994;272:222-30.

2. Schroeder SA. Training an appropriate mix of physicians to meet the nation's needs. Acad Med. 1993;68:118-22.

3. Federated Council of Internal Medicine. Reaching consensus of physician workforce policy: an opportunity for change. Am J Med. 1994;97:vi-vii.

4. Meyer GS, Jacoby I, KraKauer H, et al. Gastroenterology workforce modeling. JAMA. 1996;276:689-94.

5. Mayer RJ, Antman KH, Bailes JS, et al. The status of the medical oncology workforce: a report from an Ad Hoc Committee of the American Society of Clinical Oncology. J Clin Oncol. 1996;14:2612-21.

6. Ad Hoc Committee on Nephrology Manpower Needs. Estimating workforce and training requirements for nephrologists through the year 2010. J Am Soc Nephrol. 1997;8(suppl 9):S9-13.

7. Guadagnoli E, McNeil BJ. Outcomes research: hope for the future or the latest rage? Inquiry. 1994;31:14-24.

8. Harrold LR, Field TS, Gurwitz JH. Knowledge, patterns of care, and outcomes of care for generalists and specialists. J Gen Intern Med. 1999;14:499-511.

9. Bruer T, Goodman KJ, Malaty HM, et al. How do clinicians practicing in the US manage Helicobacter pylori-related gastrointestinal diseases? A comparison of primary care and specialist physicians. Am J Gastroenterol. 1998;93:553-61.

10. Stephenson J. Survival of patients with AIDS depends on physicians' experience treating the disease. JAMA. 1996;275:745-6.

11. Ismail N, Neyra R, Hakim R. The medical and economical advantages of early referral of chronic renal failure patients to renal specialists. Neph Dial Transplant. 1998;13(2):246-50.

12. Jollis JG, DeLong ER, Peterson ED, et al. Outcomes of acute myocardial infarction according to the specialty of the admitting physician. N Engl J Med. 1996;335:1880-7.

13. Chin MH, Wong JC, Zhang JX, Lang RM. Utilization and dosing of angiotensin-converting enzyme inhibitors for heart failure: effect of physician specialty and patient characteristics. J Gen Intern Med. 1997;12:563-6.

14. Vollmer VM, O'Hollaren M, Ettinger KM, et al. Specialty differences in the management of asthma: a cross sectional assessment of allergists' patients and generalists' patients in a large HMO. Arch Intern Med. 1997;157:1201-8.

15. Mitchell JB, Ballard DJ, Whisnant JP, Ammering CJ, Samsa GP, Matcher DB. What role do neurologists play in determining the costs and outcomes of stroke patients. Stroke. 1996;27:1937-43.

16. Langdon LO, Toskes PP, Kimball HR, and the American Board of Internal Medicine. Future roles and training of internal medicine subspecialists. Ann Intern Med. 1996;124:686-91.

17. Sarasin FP, Maschiangelo M-L, Schaller M-D, et al. Successful implementation of guidelines for encouraging the use of beta blockers in patients after acute myocardial infarction. Am J Med. 1999; 106:499-505.

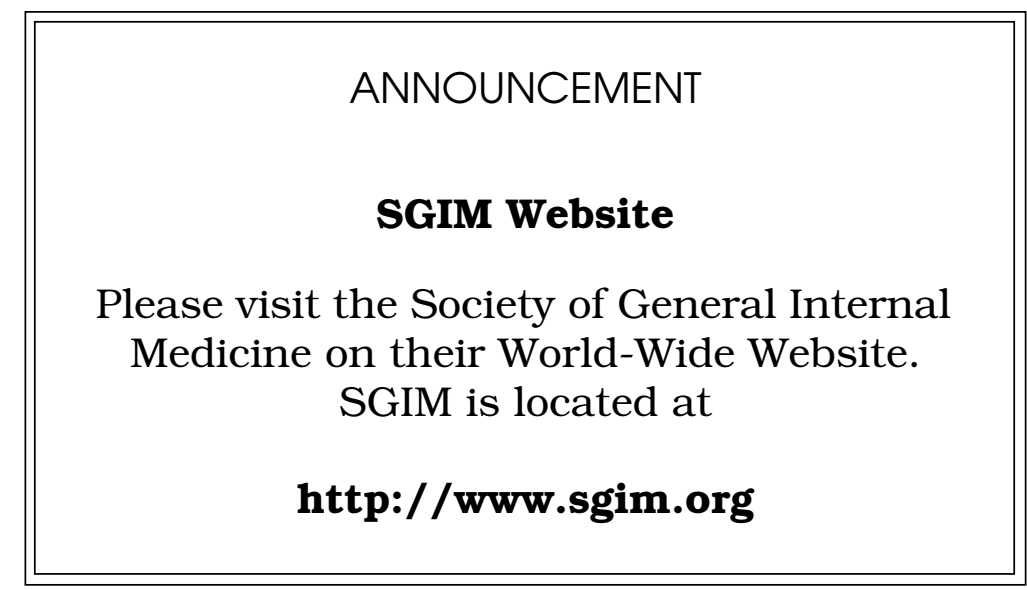

